\title{
D-Dimer Level Associates with the Incidence of Focal Neurological Deficits in Cerebral Venous Thrombosis Patients
}

This article was published in the following Dove Press journal: Journal of Blood Medicine

\author{
Cep Juli ${ }^{\prime}$ \\ Lisda Amalia \\ Uni Gamayani ${ }^{1}$ \\ Nur Atik iD ${ }^{2}$ \\ 'Department of Neurology, Dr. Hasan \\ Sadikin General Hospital/Faculty of \\ Medicine, Universitas Padjadjaran, \\ Bandung, Indonesia; ${ }^{2}$ Department of \\ Biomedical Sciences, Faculty of Medicine, \\ Universitas Padjadjaran, Bandung, \\ Indonesia
}

Purpose: D-dimer is one of the main coagulation factors that plays a role in some diseases. Cerebral venous thrombosis (CVT) is a rare cerebrovascular disease with various clinical presentations, and the D-dimer might contribute to its clinical progress. Our study's objective was to explore the association between D-dimer level and focal neurological deficits in selected CVT patients.

Patients and Methods: The patients' data were retrospectively enrolled if they showed venous thrombus features in the digital subtraction angiography examination. Data collected were then evaluated using appropriate statistical tests.

Results: In a total of 30 patients, 24 patients had focal neurological deficits with abnormal D-dimer (mean $1.13 \pm 1.359 \mathrm{mg} / \mathrm{L}$ ). We continued analysis to determine the association between the visual analog scale (VAS), a tool to measure the patient's pain, and coagulation factors. There was no significant association between the VAS score and all the coagulation factors. Interestingly, a positive association was found between focal neurological deficits and abnormal D-dimer levels ( $\mathrm{p}=0.009$ ).

Conclusion: The abnormality of D-dimer levels in CVT's patients associates with the incidence of focal neurological deficits.

Keywords: cerebral venous thrombosis, coagulation factors, D-dimer, focal neurological deficits

\section{Introduction}

CVT is a rare venous thromboembolic disease that is found three times more frequently in women compared to men. Due to hormonal factors, this disease incidence peaks among young women. ${ }^{1}$ The risk factors for this disease are usually divided into acquired risks and genetic risks. ${ }^{1,2}$ The heterogeneous etiology of CVT has made this disease a unique clinical entity because it can become the first clinical manifestation or overlap with other existing clinical problems. ${ }^{3}$

In general, thrombosis classically relates to blood stasis, endothelial injury, and coagulation disorders. ${ }^{4}$ The secondary coagulation cascade has two initial pathways: contact activation pathway (also known as the intrinsic pathway) and tissuefactor pathway (also known as the extrinsic pathway). Both pathways lead to a basic reaction, which is to produce fibrin. ${ }^{5} \mathrm{D}$-dimer is the endogenous fibrinolysis marker often used in studies related to thrombosis., ${ }^{6,7}$ Plasma D-dimer level is already proven to have a high sensitivity and specificity for CVT diagnosis. ${ }^{8-10}$ This test is frequently used in the diagnosis of CVT because it is simple and less
Correspondence: Nur Atik Department of Biomedical Sciences, Faculty of Medicine, Padjadjaran University, Bandung, Indonesia Emailn.atik@unpad.ac.id
Journal of Blood Medicine 2020:I I 449-455 
invasive. ${ }^{11}$ The D-dimer level has a positive association with the volume and size of thrombosis and has a negative association with clinical symptom duration. ${ }^{2,12}$

Cerebral venous thrombosis affects the brain main venous anatomy, leading to thrombosis in one or more blood vessels. ${ }^{4}$ The incidence of multiple venous channel involvement is higher since around two-thirds of the patients experience thrombosis in more than one venous channel. Deep venous thrombosis is far less frequent than dural sinus thrombosis. ${ }^{1}$ The most common sinus affected are superior sagittal sinus and transversal sinus. ${ }^{5}$

The clinical presentation of CVT varies in patients of different ages and different CVT topography. ${ }^{1}$ The most common signs and symptoms of CVT are headache and focal neurological deficits. ${ }^{13}$ Headache is found in almost $90 \%$ of CVT patients, which is usually non-uniform, diffuse, and often become more severe from days to weeks. The most common pattern is the sub-acute and chronic onsets with various severity levels. ${ }^{1,6,13}$ Focal neurological deficits may be seen in CVT, depending on which area is involved. ${ }^{14}$ Some CVT patients come with motoric and sensory disorders, aphasia, cranial nerve paralysis, and cortical blindness as the primary manifestations. ${ }^{4,15}$ These cranial nerve deficits may be solitary or multiple. ${ }^{12}$ The recent study, conducted by Heldner et al, predicts CVT using clinical factors and D-dimer score. The study showed that a combination of D-dimer score and clinical factors had high sensitivity to diagnose CVT. $^{16}$

Previous studies have approached the CVT disease based on its clinical features and the association with coagulation factors but had not specifically analyzed D-dimer's relationship with focal neurological deficits. Then if there was an association, whether D-dimer played a direct role in focal neurological abnormalities or a sequel from the CVT location. Therefore, we look at the role of D-dimer in focal neurological deficits in patients with CVT.

\section{Patients and Methods}

\section{Subject Selection and Study Design}

This was a cross-sectional observational analytical study on retrospective data. The CVT patients' medical records admitted to the Department of Neurology, Dr. Hasan Sadikin General Hospital from 2018 to 2020 were used as secondary data in this study. D-dimer examination was done on patients' admission time. Standard laboratory measuring of D-dimer levels was determined with an automated immunoturbidimetric assay.

The inclusion criteria were completed medical records of CVT patients with the digital subtraction angiography (DSA) examination showing venous thrombus features. DSA becomes a routine examination in our center and a gold standard to detect CVT disease. Although this examination is invasive, DSA is a safe procedure. Medical records of patients with systemic diseases or conditions affect the D-dimer level, such as pregnancy, post-partum period, recent surgery or trauma, rheumatoid arthritis, septicemia, malignancy, renal dysfunction and central nervous system infection, were excluded in this study.

Each patient record was coded anonymously to ensure confidentiality during statistical analysis. The protocol study was approved by the Padjadjaran University Ethics Research Committee and conducted in compliance with the Declaration of Helsinki.

\section{Statistical Analysis}

Categorical data are presented in number, frequency and percentage while numerical data are presented in mean, standard deviation and range. Unpaired $T$-test was used for analyzing normally distributed numerical data, while the Mann Whitney test and Wilcoxon test were used as the alternatives for non-normally distributed numerical data. To understand the association between normally distributed numerical data, Pearson's correlation test and Spearman test were used for normally and non-normally distributed data, respectively. Before comparing more than two groups, the variance homogeneity was tested using the Levene test. If data were normally distributed and had homogenous variance, one-way ANOVA was used. If not, the Kruskal Wallis test was used. P-value was used for criteria of significance with $\mathrm{p} \leq 0.05$ considered as statistically significant while $p>0.05$ was considered as nonsignificant.

\section{Results}

In this study, 57 medical records of CVT patients as baseline data were collected. Only 30 patients were in the inclusion criteria, consisting of three men $(10.0 \%)$ and 27 women $(90.0 \%)$ with an overall mean age of 40.73 \pm 9.853 . History of injectable hormonal contraceptives was identified in $30.0 \%$ of the patients and $6.7 \%$ had a history of smoking. Most patients experienced focal neurological deficits $(80.0 \%)$, such as hemiparesis and 
cranial nerve paralysis. Of all coagulation factors measured, mean abnormal values were seen in D-dimer of $0.95 \pm 1.260 \mathrm{mg} / \mathrm{L}$. These abnormal D-dimer levels were observed in 19 patients (63.3\%). Thrombosis was mostly found in left transversal sinus, which contributed $53.3 \%$ of all thrombosis locations (Table 1).

When the characteristics of the headache were assessed, it was revealed that most patients had had headaches for more than 3 months (76.7\%), with most patients experienced unilateral headache $(50.0 \%)$. Throbbing headache was the type of headache experienced by most patients $(40.0 \%)$, with half of the patients $(50.0 \%)$ found relief after taking analgesics. The factor that aggravated the headache most was physical activities (13.3\%). Among patients with accompanying symptoms, most experienced vomiting and seizure (13.3\%). The average initial VAS score (at admission) was $7.23 \pm 2.029$, with most categorized in severe category $(76.7 \%)$, while the average final VAS score at discharge was $1.97 \pm 1.608$, with most categorized as mild (83.3\%). There was a statistically significant difference between the mean VAS score at admission and at discharge, with $\mathrm{P}<0.05$. The average difference in VAS, or Delta VAS, was $-5.27 \pm 2.016$ (Table 2).

Results from Spearman's test showed a statistically insignificant difference between initial VAS score, final VAS score, and coagulation factors (Table 3). There were statistically insignificant differences between initial VAS score, final VAS score, and coagulation factors, with $\mathrm{P}>0.05$ (Table 3).

We analyzed the initial VAS category and coagulation factors to know the association amongst them. We showed that the association between the initial VAS category and coagulation factors was considered to be statistically insignificant $(\mathrm{P}>0.05)$ (Table 4).

The result of the statistical analysis of the association between final VAS score and coagulation factors showed that $\mathrm{P}$ was more than $0.05 \quad(\mathrm{P}>0.05)$, reflecting a statistically insignificant difference (Table 5).

Finally, the data were analyzed with appropriate statistic methods to understand the association between focal neurological deficits and coagulation factors. We showed $\mathrm{P}$-value in the $\mathrm{D}$-dimer variable was less than 0.05 $(\mathrm{P}<0.05)$, meaning that it was statistically significant (Table 6).

\section{Discussion}

In this study, we found more young female patients diagnosed with CVT compared to men. This is probably
Table I Basic Characteristics of CVT Patients

\begin{tabular}{|c|c|}
\hline Variables & $\mathbf{N}=\mathbf{3 0}$ \\
\hline \multicolumn{2}{|l|}{ Age (year) } \\
\hline Mean \pm Std & $40.73 \pm 9.853$ \\
\hline \multicolumn{2}{|l|}{ Sex } \\
\hline Male & $3(10.0 \%)$ \\
\hline Female & $27(90.0 \%)$ \\
\hline \multicolumn{2}{|l|}{ Length of treatment (day) } \\
\hline Mean \pm Std & $6.73 \pm 3.648$ \\
\hline \multicolumn{2}{|l|}{ Risk factors } \\
\hline History of Contraceptive Use & $9(30.0 \%)$ \\
\hline History of Smoking & $2(6.7 \%)$ \\
\hline \multicolumn{2}{|l|}{ Focal neurological deficits } \\
\hline Yes & $24(80.0 \%)$ \\
\hline No & $6(20.0 \%)$ \\
\hline \multicolumn{2}{|l|}{ Hemoglobin (g/dL) } \\
\hline Mean \pm Std & $13.14 \pm 2.085$ \\
\hline \multicolumn{2}{|l|}{ Hematocrit (\%) } \\
\hline Mean \pm Std & $40.65 \pm 7.980$ \\
\hline \multicolumn{2}{|l|}{ Trombosit (thousand/uL) } \\
\hline Mean \pm Std & $317,566.67 \pm 87,808.444$ \\
\hline \multicolumn{2}{|l|}{ Leucocyte (10^/uL) } \\
\hline Mean \pm Std & $8220.33 \pm 2557.232$ \\
\hline \multicolumn{2}{|l|}{ Fibrinogen (mg/dl) } \\
\hline Mean \pm Std & $328.35 \pm 150.258$ \\
\hline \multicolumn{2}{|l|}{ PT (second) } \\
\hline Mean \pm Std & $12.47 \pm 3.804$ \\
\hline \multicolumn{2}{|l|}{ APTT (second) } \\
\hline Mean \pm Std & $28.25 \pm 7.633$ \\
\hline \multicolumn{2}{|l|}{ INR } \\
\hline Mean \pm Std & $1.10 \pm 0.424$ \\
\hline \multicolumn{2}{|l|}{ D-dimer (mg/L) } \\
\hline Mean \pm Std & $0.95 \pm 1.260$ \\
\hline \multicolumn{2}{|l|}{ Fibrinogen category } \\
\hline Normal & $26(86.7 \%)$ \\
\hline Abnormal & $4(13.3 \%)$ \\
\hline \multicolumn{2}{|l|}{ PT category } \\
\hline Normal & $28(93.3 \%)$ \\
\hline Abnormal & $2(6.7 \%)$ \\
\hline \multicolumn{2}{|l|}{ APTT category } \\
\hline Normal & $25(83.3 \%)$ \\
\hline Abnormal & $5(16.7 \%)$ \\
\hline \multicolumn{2}{|l|}{ INR category } \\
\hline Normal & $26(86.7 \%)$ \\
\hline Abnormal & $4(13.3 \%)$ \\
\hline
\end{tabular}

(Continued) 
Table I (Continued).

\begin{tabular}{|l|l|}
\hline Variables & $\mathbf{N}=\mathbf{3 0}$ \\
\hline D-dimer category & \\
Normal & $\mathrm{I}(63.3 \%)$ \\
Abnormal & $\mathrm{II}(36.7 \%)$ \\
\hline DSA feature & \\
Right transverse sinus thrombosis & $\mathrm{I} 0(33.3 \%)$ \\
Left transverse sinus thrombosis & $\mathrm{I}(53.3 \%)$ \\
Bilateral transverse sinus thrombosis & $\mathrm{I}(3.3 \%)$ \\
Sagittal sinus thrombosis & $\mathrm{I}(3.3 \%)$ \\
Bilateral straight sinus thrombosis & $\mathrm{I}(3.3 \%)$ \\
Hemisphere thrombosis & $\mathrm{I}(3.3 \%)$ \\
\hline
\end{tabular}

Abbreviations: PT, prothrombin time; APTT, activated partial thromboplastin time; INR, international normalized ratio.

a secondary difference due to hypercoagulability related to the increase in estrogen due to pregnancy and oral contraceptive use, especially the use of combination hormonal contraceptives. These factors increase the risk for thrombosis. ${ }^{17,18}$

Coagulation disorders are the main factor of thrombosis in CVT. ${ }^{18}$ The process of thrombosis can be detected through the D-dimer level. A high D-dimer level shows a high risk for thrombosis. D-dimer is a specific antigen originating from factor XIIIa cross-linked fibrin degradation. A specific monoclonal antibody for D-dimer antigen has been developed to enable a laboratory testing that can differentiate between products originating from fibrinogen degradation and products originating from fibrin degradation. D-dimer antigen measured in clinical samples comes from fibrin degradation that comes from a joint action of thrombin, factor XIIIa, and plasmin. ${ }^{5}$ D-dimer assays are known as highly sensitive test but are often falsely positive in conditions as follows: malignancy, recent surgery or trauma, pregnancy or postpartum state and renal dysfunction. ${ }^{16}$

Our study identifies the following signs and symptoms: headache, vomiting, seizure, and focal neurological deficits. The clinical presentation of cerebral vein thrombosis may vary. There are a lot of variations in the clinical features related to CVT with symptoms and signs may appear in acutely, sub-acutely, or chronically. The severity of the clinical presentation depends on the thrombosis level, sinus involved, and venous collateral expansion. ${ }^{6,19}$

The type of headaches reported by CVT patients also varies, starting from cluster headaches, such as the worse headache onset of a lifetime, migraine, exploding
Table 2 Characteristics of Headache in CVT Patients

\begin{tabular}{|c|c|}
\hline Variables & $\mathbf{N}=\mathbf{3 0}$ \\
\hline \multicolumn{2}{|l|}{ Onset of headache } \\
\hline$<1$ month & $4(13.3 \%)$ \\
\hline I-3 months & $3(10.0 \%)$ \\
\hline$>3$ months & $23(76.7 \%)$ \\
\hline \multicolumn{2}{|l|}{ Headache location } \\
\hline Unilateral & $15(50.0 \%)$ \\
\hline Localized & $7(23.3 \%)$ \\
\hline Diffuse & $8(26.7 \%)$ \\
\hline \multicolumn{2}{|l|}{ Type of headache } \\
\hline Throbbing & $12(40.0 \%)$ \\
\hline Tension & $4(13.3 \%)$ \\
\hline Band-like & $4(13.4 \%)$ \\
\hline Stabbing & $10(33.3 \%)$ \\
\hline \multicolumn{2}{|l|}{ Relieving factors } \\
\hline Sleep & $2(6.7 \%)$ \\
\hline Lie down & $3(10.0 \%)$ \\
\hline Take medicine & $15(50.0 \%)$ \\
\hline \multicolumn{2}{|l|}{ Aggravating factors } \\
\hline Coughing & $\mathrm{I}(3.3 \%)$ \\
\hline Physical activities & $4(13.3 \%)$ \\
\hline \multicolumn{2}{|l|}{ Accompanying symptoms } \\
\hline Vomiting & $4(13.3 \%)$ \\
\hline Phonophobia & $2(6.7 \%)$ \\
\hline Photophobia & $2(6.7 \%)$ \\
\hline Seizure & $4(13.3 \%)$ \\
\hline \multicolumn{2}{|l|}{ Initial VAS } \\
\hline Mean \pm Std & $7.23 \pm 2.029$ \\
\hline Median & 8.00 \\
\hline Range (min-max) & $0.00-10.00$ \\
\hline \multicolumn{2}{|l|}{ Final VAS } \\
\hline Mean \pm Std & $1.97 \pm 1.608$ \\
\hline Median & 2.00 \\
\hline Range (min-max) & $0.00-5.00$ \\
\hline \multicolumn{2}{|l|}{ Delta VAS } \\
\hline Mean \pm Std & $-5.27 \pm 2.016$ \\
\hline Median & -5.00 \\
\hline Range (min-max) & $-8.00-0.00$ \\
\hline \multicolumn{2}{|l|}{ Initial VAS category } \\
\hline Mild & $2(6.7 \%)$ \\
\hline Moderate & $5(16.7 \%)$ \\
\hline Severe & $23(76.7 \%)$ \\
\hline \multicolumn{2}{|l|}{ Final VAS category } \\
\hline Mild & $25(83.3 \%)$ \\
\hline Moderate & $5(16.7 \%)$ \\
\hline Severe & $0(0.0 \%)$ \\
\hline
\end{tabular}

Abbreviation: VAS, visual analog scale. 
Table 3 Correlation Between Initial VAS Score, Final VAS Score, and Coagulation Factors

\begin{tabular}{|l|l|l|}
\hline Variables & Initial VAS Score & Final VAS Score \\
\hline Fibrinogen & $R=-0.107 P$ value=0.557 & $R=-0.185 P$ value $=0.329$ \\
PT & $R=0.007 P$ value $=0.970$ & $R=-0257 P$ value $=0.170$ \\
APTT & $R=0.138 P$ value $=0.466$ & $R=-0.024 P$ value $=0.898$ \\
INR & $R=-0.032 P$ value $=0.867$ & $R=-0.179 P$ value $=0.343$ \\
D-dimer & $R=-0.002 P$ value=0.993 & $R=0.085 P$ value $=0.655$ \\
\hline
\end{tabular}

Notes: Significant if $p<0.05$. R: correlation coefficient.

headache, chronic tension headache, chronic daily headache, and thunderclap headache. ${ }^{6,13}$ In our study, most patients experienced chronic headache with various types and quality of pain. Chronic headache was defined if the onset of headache more than one month. ${ }^{20}$ The presence of headache is most probably explained as originating from two main factors: the local process in the vein and dural sinus and increasing intracranial pressure. Unlike the brain, dura and venous sinus consist of fibers that are sensitive to pain. Sinus distension, especially when it is caused by inflammation, will activate those sensitive fibers. Thrombosis causes the obstruction of venous drainage from the intracranial structures. This increased venous pressure leads to increasing intracranial pressure. ${ }^{1}$

Focal neurological deficits is the most commonly identified disorder other than headache. ${ }^{15}$ The most frequently observed focal neurological deficit in CVT is motoric disorders. CVT can also trigger single or multiple cranial nerve paralysis. The involvement of cranial nerves III, IV, $\mathrm{V}$, VI, VII, VIII, IX, X, and XII have been widely
Table 5 Association Between Final VAS Score and Coagulation Factors

\begin{tabular}{|c|l|l|l|}
\hline \multirow{2}{*}{ Variables } & \multicolumn{2}{|l|}{ Final VAS Score } & \multirow{2}{*}{ P-value } \\
\cline { 2 - 3 } & Mild & Moderate & \\
\cline { 2 - 3 } & $\mathbf{N}=\mathbf{2 5}$ & $\mathbf{N}=5$ & 0.404 \\
\hline $\begin{array}{c}\text { Fibrinogen } \\
\text { Mean } \pm \text { Std }\end{array}$ & $338.80 \pm 162.712$ & $276.10 \pm 27.209$ & 0.300 \\
\hline $\begin{array}{c}\text { PT } \\
\text { Mean } \pm \text { Std }\end{array}$ & $12.72 \pm 4.108$ & $11.20 \pm 1.105$ & 0.988 \\
\hline $\begin{array}{c}\text { APTT } \\
\text { Mean } \pm \text { Std }\end{array}$ & $28.24 \pm 8.252$ & $28.30 \pm 3.717$ & 0.300 \\
\hline $\begin{array}{c}\text { INR } \\
\text { Mean } \pm \text { Std }\end{array}$ & $1.13 \pm 0.462$ & $0.97 \pm 0.039$ & 0.448 \\
\hline $\begin{array}{c}\text { D-dimer } \\
\text { Mean } \pm \text { Std }\end{array}$ & $1.07 \pm 1.354$ & $0.38 \pm 0.111$ & \\
\hline
\end{tabular}

reported. Focal neurological deficits observed will depend on the location of the thrombus and correlate with larger cerebral infarction. ${ }^{5,15}$ Motoric deficit and cranial nerve involvement are often seen in patients with a lesion in the transversal sinus. ${ }^{15}$ D-dimer had an association to infarct volume and neurological deficits. Positive examination of D-dimer results indicate the presence of a thrombus, but cannot indicate the location and rule out other potential etiologies. D-dimer examination is useful to determine the formation of abnormal blood clots or the presence of thrombotic and to determine the presence of clot lysis or fibrinolytic processes. ${ }^{5,10,15}$ Thrombosis

Table 4 Association Between Initial VAS Category and Coagulation Factors

\begin{tabular}{|c|c|c|c|c|}
\hline \multirow[t]{3}{*}{ Variables } & \multicolumn{3}{|c|}{ Initial VAS Category } & \multirow[t]{3}{*}{ P-value } \\
\hline & Mild & Moderate & Severe & \\
\hline & $\mathbf{N}=\mathbf{2}$ & $N=5$ & $\mathbf{N}=\mathbf{2 3}$ & \\
\hline $\begin{array}{r}\text { Fibrinogen } \\
\text { Mean } \pm \text { Std }\end{array}$ & $408.00 \pm 45.255$ & $317.80 \pm 85.036$ & $323.72 \pm 166.520$ & 0.436 \\
\hline $\begin{array}{l}\text { PT } \\
\quad \text { Mean } \pm \text { Std }\end{array}$ & $14.45 \pm 3.465$ & $11.26 \pm 0.770$ & $12.56 \pm 4.209$ & 0.332 \\
\hline $\begin{array}{l}\text { APTT } \\
\qquad \text { Mean } \pm \text { Std }\end{array}$ & $33.65 \pm 0.212$ & $25.12 \pm 3.968$ & $28.46 \pm 8.307$ & 0.409 \\
\hline $\begin{array}{l}\text { INR } \\
\quad \text { Mean } \pm \text { Std }\end{array}$ & $1.35 \pm 0.396$ & $0.98 \pm 0.099$ & $1.11 \pm 0.468$ & 0.248 \\
\hline $\begin{array}{l}\text { D-dimer } \\
\text { Mean } \pm \text { Std }\end{array}$ & $0.35 \pm 0.226$ & $1.59 \pm 2.078$ & $0.87 \pm 1.084$ & 0.216 \\
\hline
\end{tabular}


Table 6 Association Between Focal Neurological Deficits and Coagulation Factors

\begin{tabular}{|c|l|l|l|}
\hline \multirow{2}{*}{ Variables } & \multicolumn{2}{|l|}{ Focal Neurological Deficits } & \multirow{2}{*}{ P-value } \\
\cline { 2 - 3 } & Yes & No & \\
\cline { 2 - 3 } & $\mathbf{N}=\mathbf{2 4}$ & $\mathbf{N}=6$ & 0.296 \\
\hline $\begin{array}{c}\text { Fibrinogen } \\
\text { Mean } \pm \text { Std }\end{array}$ & $347.72 \pm 159.576$ & $250.88 \pm 69.350$ & \\
\hline $\begin{array}{c}\text { PT } \\
\text { Mean } \pm \text { Std }\end{array}$ & $12.64 \pm 4.225$ & $11.78 \pm 1.039$ & 0.860 \\
\hline $\begin{array}{c}\text { APTT } \\
\text { Mean } \pm \text { Std }\end{array}$ & $28.37 \pm 8.322$ & $27.78 \pm 4.359$ & 0.870 \\
\hline $\begin{array}{c}\text { INR } \\
\text { Mean } \pm \text { Std }\end{array}$ & $1.12 \pm 0.474$ & $1.02 \pm 0.044$ & 0.781 \\
\hline $\begin{array}{c}\text { D-dimer } \\
\text { Mean } \pm \text { Std }\end{array}$ & $1.13 \pm 1.359$ & $0.27 \pm 0.100$ & $0.009 *$ \\
\hline
\end{tabular}

Note: *Statistically significant with $\mathrm{p}$ value $<0.05$.

contributes to focal neurological deficits by causing brain perfusion reduction as well as cytotoxic and vasogenic edema which then lead to ischemic injuries and vein and capillary rupture, causing parenchymal bleeding. ${ }^{6,19}$

Magnetic resonance venography (MRV) has now become the most commonly used blood vein imaging modality for confirming CVT diagnosis. ${ }^{1,15} \mathrm{MRV}$ is limited by artifacts when identifying vascular anatomy and pathology. ${ }^{21}$ DSA is still the standard reference for most vascular imaging. Cerebral intraarterial angiography with venous phase imaging is an invasive diagnostic technic reserved for rare occasions when there is a strong clinical suspicion of cerebral vein thrombosis but the MRV result is inconclusive. ${ }^{18}$ The lack of turbidity in a part of or in the overall venous channel is a primary angiographic proof of venous occlusion. Delayed drainage and dilatation of collateral venous channel are among other signs that are commonly observed. ${ }^{1}$

This study has a limitation. It has not been able to determine wether D-dimer directly affects the location of focal neurological deficits or only from the sequel.

\section{Conclusion}

Our results suggest that the D-dimer level could be used as an indicator of the presence of focal neurological deficits in CVT patients.

\section{Acknowledgments}

We would like to thank all the staff members of Hasan Sadikin Hospital for their contribution during data collection. This work was supported by grant from Universitas Padjadjaran and the Ministry of research, and Technology/BRIN of the Republic of Indonesia to NA.

\section{Disclosure}

The authors report no conflicts of interest in this work.

\section{References}

1. Caplan LR, editor. Caplan's Stroke. Cambridge University Press; 2016:544-565.

2. Crassard I, Soria C, Tzourio C, et al. A negative D-dimer assay does not rule out cerebral venous thrombosis: a series of seventy-three patients. Stroke. 2005;36(8):1716-1719. doi:10.1161/01.STR.000 0173401.76085 .98

3. Akila A, Ananthi M, Manojkumar V. Evaluation of plasma D-Dimer as an initial diagnostic biomarker incerebral venous thrombosisa prospective cross sectional study. IOSR J Dental Med Sci. 2017;16(5):41-46. doi:10.9790/0853-1605034146

4. O'Keefe YA, Kranz PG, Dombrowski KE, Kolls BJ, James ML. Cerebral venous thrombosis: reviewing pathophysiology, diagnosis, and treatment strategies. J Neuroanaesth Crit Care. 2019; Jun (02):140-144.

5. Greenberg CS. The role of D-dimer testing in Clinical Hematology and Oncology. Clin Adv Hematol Oncol. 2017;1(15):580-583.

6. Saposnik G, Barinagarrementeria F, Jr RD B, et al. Diagnosis and management of cerebral venous thrombosis: a statement for healthcare professionals from the American Heart Association/American Stroke Association. Stroke. 2011;42(4):1158-1192. doi:10.1161/ STR.0b013e31820a8364

7. Itrat A, Shoukat S, Kamal AK. Pathophysiology of cerebral venous thrombosis-an overview. J Pak Med Assoc. 2006;56(11):506.

8. Tanislav C, Siekmann R, Sieweke N, et al. Cerebral vein thrombosis: clinical manifestation and diagnosis. BMC Neurol. 2011;11(1):69. doi:10.1186/1471-2377-11-69

9. Alons IM, Jellema K, Wermer MJ, Algra A. D-dimer for the exclusion of cerebral venous thrombosis: a meta-analysis of low risk patients with isolated headache. BMC Neurol. 2015;15(1):118. doi:10.1186/s12883-015-0389-y

10. Misra UK, Kalita J, Bansal V. D-dimer is useful in the diagnosis of cortical venous sinus thrombosis. Neurol India. 2009;57(1):50. doi:10.4103/0028-3886.48822

11. Al-Hashel J, Youssry DO, Ahmed S, Ismail I, Vembu P. The value of D-dimer test for diagnosis of cerebral venous thrombosis in Kuwait neurological center. J Neurol Sci. 2015;15(357):e363. doi:10.1016/j. jns.2015.08.1304

12. Al-Sulaiman A. Clinical aspects, diagnosis and management of cerebral vein and dural sinus thrombosis: a literature review. Saudi J Med Med Sci. 2019;7(3):137.

13. Ferro JM, de Sousa DA. Cerebral venous thrombosis: an update. Curr Neurol Neurosci Rep. 2019;19(10):74. doi:10.1007/s11910019-0988-x

14. Shahid R, Zafar A, Nazish S, et al. Etiologic and clinical features of cerebral venous sinus thrombosis in Saudi Arabia. J Neurosci Rural Pract. 2019;10(2):278. doi:10.4103/jnrp.jnrp_305_18

15. Luo Y, Tian X, Wang X. Diagnosis and treatment of cerebral venous thrombosis: a review. Front Aging Neurosci. 2018;30(10):2.

16. Heldner MR, Suurbier S, Li B, et al. Prediction of cerebral venous thrombosis with a new clinical score and D-dimer levels. Neurology. 2020;95(7):e898-e909. doi:10.1212/WNL.0000000000 009998

17. Coutinho JM, Ferro JM, Canhao P, et al. Cerebral venous and sinus thrombosis in women. Stroke. 2009;40(7):2356-2361. doi:10.1161/ STROKEAHA.108.543884 
18. Delahanty LF, Parker TGA. Case of central venous sinus thrombosis in a young woman. Clin Pract Cases Emerg Med. 2019;3(4):345. doi:10.5811/cpcem.2019.6.42988

19. Piazza G. Cerebral venous thrombosis. Circulation. 2012;125 (13):1704-1709. doi:10.1161/CIRCULATIONAHA.111.067835

20. Damak M, Crassard I, Wolff V, Bousser MG. Isolated lateral sinus thrombosis: A series of 62 patients. Stroke. 2009;40:476-481. doi:10.1161/STROKEAHA.107.509711
21. White JB, Kaufmann TJ, Kallmes DF. Venous sinus thrombosis: a misdiagnosis using MR angiography. Neurocrit Care. 2008;8 (2):290-292. doi:10.1007/s12028-007-9032-0

\section{Publish your work in this journal}

The Journal of Blood Medicine is an international, peer-reviewed, open access, online journal publishing laboratory, experimental and clinical aspects of all aspect pertaining to blood based medicine including but not limited to: Transfusion Medicine; Blood collection, Donor issues, Transmittable diseases, and Blood banking logistics; Immunohematology; Artificial and alternative blood based

Submit your manuscript here: http://www.dovepress.com/journal-of-blood-medicine-journal therapeutics; Hematology; Biotechnology/nanotechnology of blood related medicine; Legal aspects of blood medicine; Historical perspectives. The manuscript management system is completely online and includes a very quick and fair peer-review system. Visit http://www.dovepress.com/testimonials.php to read real quotes from published authors. 